\title{
LAZER, EDUCAÇÃO FÍSICA ESCOLAR E ADOLESCÊNCIA ${ }^{1}$
}

\author{
Recebido em: 12/12/2014
}

Aceito em: 07/06/2015

\author{
Vagner Miranda da Conceição ${ }^{2}$ \\ Universidade Federal de Minas Gerais \\ Belo Horizonte - MG - Brasil \\ Luciana Karine de Souza ${ }^{3}$ \\ Universidade Federal de Minas Gerais \\ Belo Horizonte - MG - Brasil
}

RESUMO: O objetivo deste estudo foi analisar a percepção de 18 adolescentes de uma escola pública de Ribeirão das Neves sobre lazer, educação física e da relação entre estas áreas. A fundamentação teórica teve como base a ciência interdisciplinar do desenvolvimento humano, os estudos do lazer e trabalhos empíricos sobre adolescência, educação física e lazer. A coleta de dados envolveu entrevista semiestruturada individual e, posteriormente, grupo focal com nove dos 18 estudantes. As respostas foram analisadas e geraram categorias temáticas semelhantes em sentido. O lazer para estes escolares é fazer o que gosta, diversão e liberdade. Críticas e anseios acerca da educação física foram referenciados, assim como a associação desta disciplina com atividade física. A relação lazer e educação física se dá pela diversão, fazer o que gosta e esportes/jogos. A vivência do lazer na escola pode promover o desenvolvimento do adolescente.

PALAVRAS CHAVE: Atividades de Lazer. Educação física e Treinamento. Adolescente.

\section{LEISURE, SCHOLAR PHYSICAL EDUCATION AND ADOLESCENCE}

ABSTRACT: The aim of this study was to analyze how 18 adolescents from a public school in Ribeirão das Neves (southeastern Brazil) understand leisure, physical education and how these areas may interact. The theoretical background was based on interdisciplinary science on human development, leisure studies, and empirical studies on adolescence, physical education, and leisure. Data collection involved an individual semi-structured interview and, later, a focus group with nine of the 18 students. The

\footnotetext{
${ }^{1}$ Este trabalho é parte inédita da Dissertação de Mestrado do primeiro autor, sob orientação da segunda autora. Agradecimentos: A. Moura, M. Rocha, H. Isayama, E. Stoppa e A. Almeida Jr. Apoio: CAPES; PPGIEL-UFMG.

${ }^{2}$ Doutorando e Mestre pelo Programa de Pós-Graduação Interdisciplinar em Estudos do Lazer (PPGIELUFMG).

${ }^{3}$ Doutora em Psicologia (UFRGS). Docente Permanente no Programa de Pós-Graduação Interdisciplinar em Estudos do Lazer (PPGIEL-UFMG).
} 
answers were analyzed and generated thematic categories according to similar content. Leisure for these students is doing what you like, having fun and freedom. There were criticisms and concerns about physical education, as well as its association with physical activity. The relationship leisure-physical education occurs via having fun, doing what you like, and sports/games. The experience of leisure at school may promote adolescent development.

KEYWORDS: Leisure Activities. Physical Education and Training. Adolescent.

A adolescência é um período do desenvolvimento humano que envolve mudanças físicas, cognitivas e emocionais marcantes. O momento de lazer e a aula de educação física escolar (EFE) são tempos e espaços que podem contribuir para o desenvolvimento do adolescente. Portanto, é relevante investigar e compreender como ele entende e vivencia o lazer e a EFE.

\section{Desenvolvimento humano e adolescência}

O desenvolvimento humano se processa partir das mudanças que ocorrem no sujeito a partir da interação deste com o contexto que o cerca (ASPESI et al, 2005). As condições de vida, o ambiente físico, as pessoas, dentre outros aspectos, são peças integrantes do contexto e, quando estas são relacionadas com idade, gênero, trajetórias de vida etc., podem interferir e assumir diferentes características quando este contexto é variado (ASPESI et al, 2005). Segundo essa abordagem atual da ciência do desenvolvimento, as interações humanas são complexas, dinâmicas e multifacetadas e, portanto, necessitam de uma visão interdisciplinar para compreender as mudanças e estabilidades ao longo da vida.

O desenvolvimento humano pode ser dividido em oito etapas, sendo a adolescência a quinta (12-20 anos), encerrada, segundo muitos desenvolvimentistas, quando o sujeito se torna independente dos pais ao ingressar no mercado de trabalho 
(SHAFFER \& KIPP, 2012). Abrange transformações físicas, emocionais e sociais advindas de alterações hormonais pertinentes à puberdade. O adolescente passa por grandes oscilações diárias de humor, possui elevada sensibilidade emocional e uma tendência maior a correr riscos, na comparação com outras etapas da vida (BELSKY, 2010). Outra característica da adolescência é a preferência pela companhia de pessoas de faixa etária e interesses semelhantes.

Um aspecto que merece destaque no desenvolvimento psicológico na adolescência é o egocentrismo. Segundo o pesquisador David Elkind, trata-se de uma percepção distorcida através da qual o adolescente tende a se ver como foco da atenção das pessoas à sua volta (BELSKY, 2010). Este egocentrismo adolescente opera por dois mecanismos: o público imaginário (a sensação de estar em um palco, sendo observado com atenção por todos ao redor) e a fábula pessoal (o sentimento de que a própria vida é especial, única e original, ou seja, tudo o que lhe ocorre é sempre vivenciado como a melhor ou a pior das situações, na comparação com qualquer outra pessoa, ou mesmo como o único a experimentar esta ou aquela dificuldade) (BELSKY, 2010). Diante disso, para uma melhor compreensão de como o adolescente percebe o mundo à sua volta, é necessário considerar tais mecanismos. Entende-los e como eles podem influenciar a interação do adolescente com o contexto é, portanto, relevante para o presente estudo, que busca conhecer sua percepção sobre lazer e EFE.

Têm sido frequentes as publicações na área dos estudos do lazer considerando a juventude, na comparação com a adolescência. As publicações calcadas em abordagens mais sociológicas e/ou históricas preferem o termo juventude. Mais especificamente, empregam este termo para se referir a uma categoria social, a um segmento populacional, a uma geração em um dado contexto histórico, ou a atores sociais 
(FREITAS, 2005). De outro lado, adolescente/adolescência são preferidos por estudos com abordagem psicológica quando se tem o intuito de abordar a fase da vida iniciada pela puberdade e encerrada por tarefas sociais que anunciam a entrada na vida adulta. A adolescência envolve um conjunto de oscilações emocionais e comportamentais e, por esta razão, estudos psicológicos interessados nos pensamentos, sentimentos e/ou comportamentos do adolescente precisam tomar parte dos aspectos específicos ao desenvolvimento cognitivo, físico e socioemocional nesta etapa da vida (BELSKY, 2010), que é por onde também perpassa este estudo.

\section{O lazer e a adolescência}

$\mathrm{Na}$ sua relação com a sociedade, o lazer apresenta três valores: o descanso, o divertimento e o desenvolvimento pessoal e social (DUMAZEDIER, 1980). Estas dimensões são dinâmicas culturais do comportamento humano, aonde cada qual, em determinado momento da vida e de acordo com os interesses do sujeito, irão se sobressair e predominar. Entre elas há fronteiras intercambiáveis e para a vivência de um lazer de qualidade é necessário um equilíbrio entre elas (MARCELLINO, 2006).

O lazer pode ser definido como "necessidade humana e dimensão da cultura caracterizada pela vivência lúdica de manifestações culturais no tempo/espaço social" (GOMES, 2011, p.34). Aproximando esta definição à de Dumazedier (1980), percebese que os três valores por ele elencados são necessidades humanas e que, enquanto valores, apresentam conteúdos distintos conforme o grupo cultural humano que o vivencia e a ele dá sentido. Ademais, as dimensões temporais e espaciais são necessárias para a compreensão das práticas culturais que mudam com o passar do tempo, bem como mudam ao longo do desenvolvimento de uma pessoa; já no caso do 
espaço, entende-se que os contextos de interação com outras pessoas são variados na vida de um sujeito, mudam com o desenvolvimento deste, que os transforma e por eles é transformado. Assim, encontram-se pontos em comum entre os entendimentos do lazer conforme Dumazedier (1980), Marcelino (2006) e Gomes (2011), e a definição de desenvolvimento humano de Belsky (2010) e de Shaffer e Kipp (2012).

Especificamente com respeito ao lazer na adolescência, Bonato, Sarriera e Wagner (2012) o consideram tanto uma oportunidade de desenvolvimento como de risco. Belsky (2010) salienta que ter amigos que sejam pró-sociais, ser bem sucedido em atividades escolares e ter um hobby (por exemplo, uma prática esportiva) são aspectos que pesam para que o lazer seja um fator protetivo ao desenvolvimento do adolescente. Como fator de risco, Belsky (2010) cita as amizades antissociais (que reforçam, entre si, a prática de atividades perigosas) e o envolvimento com drogas. Nesse sentido, o lazer na adolescência oportuniza um leque de possibilidades interacionais, positivas ou negativas, nesta fase da vida (ASPESI et al., 2005; BONATO; SARRIERA; WAGNER, 2012).

Das publicações nacionais na forma de artigos científicos sobre lazer na adolescência com dados coletados em escolas, foi possível localizar poucos trabalhos. Estas publicações são resumidas e comentadas a seguir, dada a aproximação com os objetivos ou com as expectativas do presente estudo.

Formiga; Ayrosa e Dias (2005) investigaram os hábitos de lazer de 710 estudantes (11-22 anos) de João Pessoa (PB). Os hábitos de lazer identificados foram categorizados pelos autores como hedonistas (lazer cuja característica predominante é a satisfação pessoal e imediata de um desejo), lúdicos (relacionados ao caráter instrumental do lazer) e instrutivos (relacionados "à transmissão, à habilitação e ao 
ensino de conhecimentos", p.76). Estes três hábitos segundo Formiga; Ayrosa e Dias (2005) e os três valores de Dumazedier (1980) são inerentes à vivência do lazer. Por vezes, um se sobressai ao outro, mas todos têm potencial para promover, ou inibir, desenvolvimento humano.

Pratta e Santos (2007) abordaram 568 adolescentes (14-20 anos), estudantes do ensino médio (EM) em escolas da cidade de São Carlos (SP), e encontraram uma associação entre tipo de lazer e uso de substâncias psicoativas (exceto tabaco e álcool). Os adolescentes não-usuários apontaram mais "ir à Igreja ou serviço religioso", "praticar esportes" e "sair com a família" como práticas de lazer. Os usuários citaram mais "frequentar clubes/praias", "sair com amigos" e "frequentar bares". É comum a indicação da ocupação do tempo livre como estratégia para prevenção ao uso de substâncias psicoativas. No entanto, mais do que ocupar o tempo do adolescente, cabe analisar quais atividades lhe proporcionam descanso, divertimento, prazer e desenvolvimento saudável, capazes de despertar seu interesse e fazer sentido às suas vivências culturais. Além disso, tanto a importância que os usuários deram à companhia dos amigos no estudo de Pratta e Santos (2007), quanto o fato de que a maior parte dos amigos do adolescente estão na sua turma escolar, colaboram para que a EFE traga o lazer para dentro da escola.

O trabalho de Silva e Xavier (2006) buscou conhecer o lazer de 66 alunos (média etária de 18 anos) do EM de duas escolas do Rio de Janeiro: uma federal (Colégio A, de classe social elevada) e outra estadual (Colégio B, de classe pobre, conforme referido pelos autores). Os alunos do Colégio A definiram o lazer como relaxamento, momento da não-obrigação e da livre escolha. Os alunos do Colégio B associaram o lazer a atividades práticas e ao fazer nada. A escola é um local de lazer 
para os alunos do Colégio A pelo contato com amigos, prática esportiva e possibilidade de escolha, ainda que tenham obrigações escolares. Para os alunos do Colégio B o espaço escolar é favorável à prática do lazer devido às amizades, momentos fora da sala de aula e à possibilidade de distração, ainda que a escola seja um local muito sério e fechado a possibilidades de ensino-aprendizagem. O estudo de Silva e Xavier (2006) mostra que a aula de EF tem grande potencial, portanto, para ofertar lazer, ou seja, um tempo e espaço de aprendizado prazeroso e promotor de desenvolvimento pessoal e social, nos níveis físico, cognitivo, emocional e comportamental. Dessa forma, há claros precedentes para a junção lazer-EFE que se pretende no presente estudo.

Hardman et al. (2013) analisaram a relação entre participação nas aulas de EF e atitudes sobre atividade física (gostar de fazer e preferir atividades de lazer fisicamente ativas) em 4207 estudantes pernambucanos de 14 a 19 anos. Foi detectada uma relação positiva e direta entre participação nas aulas de EF e atitudes relacionadas à atividade física. Isso sugere que a EF pode instrumentalizar e desenvolver hábitos saudáveis de lazer fora do ambiente escolar.

A seguir, são apresentados apontamentos acerca da relação lazer-EF. Pretende-se considerar o lazer como prática e conteúdo presente na escola e, em especial, na EFE.

\section{Educação Física Escolar (EFE) e Lazer}

A presente pesquisa focaliza a área da EFE, definindo-a como "prática pedagógica que, no âmbito escolar, tematiza formas de atividades expressivas corporais", a cultura corporal (SOARES et al., 1992, p. 33). Além de tratar do ensinoaprendizagem dos conteúdos da cultura corporal, a EFE também objetiva proporcionar discussões e reflexões filosóficas, científicas, políticas e culturais. Nesse contexto, o 
lazer é conteúdo altamente pertinente. Em 1980, Requixa já argumentava em prol da função educativa do lazer. Mais tarde, Marcellino (2006) salientava o duplo aspecto educativo do lazer: o educar para e pelo lazer.

O lazer, a escola e o processo educativo relacionam-se de modo interdependente (MARCELLINO, 2010). Três aspectos se destacam nessa relação lazer-EF: a) tempo/espaço para reflexão acerca da importância do lazer na sociedade; b) contribuição para a elucidação da relação conteúdos físico-esportivos e conteúdos culturais; e c) trato, não somente prático, dos conteúdos, mas também como apuração do gosto na formação de espectadores ativos (MARCELLINO et al., 2001).

$\mathrm{Na}$ maior parte das vezes as atividades físico-esportivas ocorrem por livre adesão e em tempo/espaço sem obrigações, ou seja, como manifestações de lazer (MARCELLINO, 2006). No entanto, esta afirmação não condiz com a realidade escolar, pois mesmo que seja percebida como um momento despretensioso, a aula de EF acontece em tempo/espaço regulamentado e com objetivos pré-definidos pelo professor.

O presente trabalho objetivou analisar a percepção de alunos adolescentes sobre lazer, EFE e a relação entre estas áreas. Para tanto, buscou-se amparo na psicologia do desenvolvimento do adolescente, bem como em pesquisas nacionais envolvendo adolescentes, lazer e educação física.

\section{Procedimentos metodológicos}

Fizeram parte deste estudo 18 escolares adolescentes (9 moças e 9 rapazes), na faixa etária de 16 a 18 anos. A escola foi selecionada por critério de conveniência e por ser o local da prerrogativa motivadora deste trabalho. Os estudantes foram entrevistados individualmente e, posteriormente, foram selecionados, e convidados, 10 alunos para 
participar de um grupo focal (GF). Destes, 9 participaram, pois um aluno se desligou da escola. Os participantes responderam a questões de envolvimento em trabalho, estudos e cursos complementares e atividades de lazer. A seleção das pessoas para o GF foi regida por dois critérios: a homogeneidade e a heterogeneidade (BARBOUR, 2009). A questão escolhida como alvo de análise do grupo foi “Existe alguma relação entre Lazer e EF?".

Dois avaliadores treinados executaram a análise das transcrições das respostas às entrevistas e ao GF, consultando um terceiro avaliador para dirimir dúvidas. Foram construídas categorias de respostas com base em unidades temáticas semelhantes em sentido, baseadas nos princípios da análise de conteúdo qualitativa de Bardin (2011). Este estudo foi aprovado pelo Comitê de Ética em Pesquisa da UFMG (COEP-UFMG), sob o protocolo CAAE 0548012.6.0000.5149.

\section{Resultados e discussão: A percepção dos adolescentes sobre o lazer}

\section{Lazer é fazer o que se gosta}

Nas entrevistas individuais, para a pergunta "Para você, o que é Lazer?" a análise possibilitou a construção de sete categorias de respostas. As três com maior frequência de respostas foram: Diversão (11 respostas, sendo 6 rapazes e 5 moças); Fazer o que gosta (4 rapazes e 7 moças), incluindo os conteúdos "coisas boas da vida", "sentir-se bem", "prazer" e "lazer faz bem"; e Liberdade (3 rapazes e 3 moças), abrangendo "fazer o que quer", "momento livre", "sem regras", "ficar à vontade", e "sem horário fixo". As demais categorias foram tranquilidade/descanso/relaxamento, desenvolvimento, outros elementos, e atividades variadas.

No GF, para a pergunta “O que é lazer?”, os seguintes temas se destacaram na discussão: a) momento de descontração com desconexão das responsabilidades diárias; 
b) diversão, sair da rotina com alguém; c) fazer o que gosta, o que quer, por vontade própria; d) momento que você se desliga das responsabilidades diárias - escola e trabalho; e) algo diferente ou não, mas que traga bem-estar e diversão, uma distração com algum benefício: usufruindo de forma correta algo que aprendeu; e) sair da rotina, esquecer do mundo e fazer algo para você mesmo; f) fazer algo que faz bem para você mesmo, que lhe faz sentir bem.

Tanto individualmente, como no GF, Fazer o que gosta sugere que o lazer é momento de busca por e vivência de prazer e satisfação pessoal (DUMAZEDIER, 2008). Se tal satisfação não é alcançada, o lazer em si se desfigura. Os resultados encontrados se aproximam dos hábitos hedonistas sugeridos por Formiga; Ayrosa e Dias (2005). Tanto estes autores como Dumazedier (2008) argumentam pela dimensão da satisfação pessoal e imediata de um desejo/prazer individual.

Nas entrevistas individuais, uma pessoa afirmou que o uso de drogas é uma prática de lazer "não sério", porque o lazer sério envolve reflexão sobre o que se pratica e a ausência de prejuízo à saúde ou à vida em geral. Rojek (2011) destaca um lado obscuro do lazer, qual seja, a satisfação pessoal através de atividades depreciativas à vida, como o abuso no consumo de bebida alcoólica, uso de drogas ilícitas, envolvimento com atividades criminosas etc. Também Munné e Codina (2002) referem que uma das características do lazer é sua ambivalência: momento potencial para o desenvolvimento e vivência de ações criativas e/ou momento de usufruir de atividades desviantes ou formas anormais de lazer (ROJEK, 2011).

Os adolescentes deste estudo moram em uma região em que o tráfico de drogas é bastante presente. Além disso, na adolescência o sujeito costuma correr riscos, desobedecer e desafiar limites, bem como acreditar que tudo o que se passa consigo é 
único e especial (resultado do mecanismo psicológico da fábula pessoal) (BELSKY, 2010).

Portanto, é essencial que os governantes compreendam que o lazer também é uma necessidade desenvolvimental do adolescente e que requer programas e políticas públicas de abordagem interdisciplinar, buscando compreender e estabelecer vínculos positivos a partir da complexa interação sujeito-contexto-desenvolvimento (ASPESI et al., 2005). Defende-se um lazer capaz de desenvolver nos adolescentes valores e percepções diferentes acerca dos seus contextos de vida. Não se está propondo um lazer de cunho moralista (MARCELLINO, 2010), não se está propondo que todo adolescente de região carente usa o tempo livre para ingressar no crime, e nem projetos de lazer para "domesticar as massas". Acredita-se no potencial que o lazer tem de divertir, educar e contribuir positivamente para o desenvolvimento do adolescente.

Segundo os adolescentes que participaram desta pesquisa, há duas dimensões essenciais para o divertir-se: a autonomia, para a escolha de o que, quando e como se divertir; e a responsabilidade para retornar às obrigações após a diversão ou distração. Dessa forma, o lazer para o adolescente também envolve reflexão sobre sua capacidade de escolha e de manutenção de práticas de lazer, principalmente considerando-se o pensamento distorcido próprio do egocentrismo adolescente (BELSKY, 2010) e a visão de que todas as suas ações estão no centro das atenções de todos. Por fim, na adolescência aumenta a pressão social para inserção no mercado de trabalho e/ou no ensino superior. Dessa forma, o lazer como diversão desvia a atenção das obrigações para a vivência, ainda que curta, de uma realidade paralela de prazer e satisfação pessoal. 


\section{Lazer é liberdade}

Segundo os adolescentes, lazer é liberdade, pois possibilita contrariar a regra adulta. Estes sujeitos, que estão em desenvolvimento e passando por alterações físicas e emocionais marcantes, querem, nesta fase da vida, viver a vida a seu modo e sem interferências adultas que possam colocar em risco o domínio sobre a própria vida.

Para Dumazedier (1976) uma das características do lazer é o caráter liberatório. No entanto, o lazer é resultado da livre escolha, da liberação de obrigações cotidianas tempo em que as restrições que governam nosso comportamento são diminuídas. Segundo Paradiso et al. (2012), as atividades de lazer no tempo livre podem ser analisadas sob a perspectiva da liberdade, pois é neste momento que se exercita a liberdade de escolha para a satisfação de um dado interesse.

A liberdade desejada pelos adolescentes pode ser vista como via de desenvolvimento pessoal para exercitar autonomia e arcar com as consequências de suas escolhas. Ademais, no tempo de lazer as restrições que regem nosso comportamento, como em outras dimensões da vida, são diminuídas. No caso dos adolescentes este é o momento em que as amarras são descartadas e este sujeito age conforme seus desejos e vontades. A liberdade entendida como expressão e manifestação da autonomia, sem controle ou regras, também foi relatada por Sarriera et al (2007) no estudo que focalizou a percepção de adolescentes acerca do tempo livre.

No entanto, o adolescente não é mais a criança que necessita de auxílio para realizar todas as suas tarefas, mas também ainda não é, cognitiva e emocionalmente, um adulto capaz de fazer escolhas bem deliberadas e arcar suas consequências (OZELLA, 2002). Neste sentido, esta relação constante de busca pela liberdade e cobrança por limites precisa ser refletida, pois pode interferir na construção da identidade 
adolescente. Porque ainda em desenvolvimento, necessitam de orientação diante de escolhas.

\section{A percepção dos adolescentes sobre a aula de Educação Física}

A análise das respostas individuais à pergunta "Para você o que é educação física?" levou à construção de sete categorias. Três receberam mais respostas dos participantes: 1) Críticas à EF (4 rapazes e 7 moças), composta por conteúdos como "excesso de liberdade", "falta de comando do(a) professor(a)", "falta de criatividade", "fica-se só conversando", "falta de espaço na quadra", "a bola é só para os meninos", "fíca-se à toa", "põe-se a fofoca em dia", "é regular, incompleta", "deveria ser variada", e "deveria ser melhor"; 2) Corpo, Exercício e Atividade Física (7 rapazes e 4 moças), envolvendo conteúdos como "atividades físicas", "cuidar do corpo", "interagir com o corpo", "habilidades do corpo", "estar bem com o corpo", "exercitar", "aparência física", e "academia"; e 3) Quer Aprender (4 rapazes e 2 moças), com "vontade de aprender", "esporte em grupo", “outros esportes", "novos exercícios, atividades", e as sugestões de inclusão, nas aulas de EF, de peteca, handebol, queimada, futsal e/ou vôlei. As demais categorias foram esportes/jogos, avaliação, aprendizado na EF e liberdade.

No GF, a primeira pergunta, “Como seria uma boa aula de EF?", foi apresentada em virtude dos anseios e críticas que surgiram nas entrevistas individuais. A discussão no GF também trouxe conteúdos de que a aula de EF não é boa, de qualidade, nem satisfaz, porque: a)falta uma atitude de autoridade no(a) professor(a); b)os rapazes pressionam o(a) professor(a) para a prática fora de sala focalizando o futsal; c)as moças se acomodaram com a situação preferindo não discutir nem se indispor com os colegas 
de turma sempre cedendo a eles o espaço de aula para a prática do futsal; d)alunos e alunas desconhecem o sentido da escola e da disciplina EF para a vida, assim como para o futuro; e)os governos, via escola, não oferecem suporte financeiro a esta disciplina; f)a direção da escola não direciona seu olhar para a disciplina de EF; g)a disciplina de EF não transmite conteúdos relevantes.

\section{A aula de Educação Física precisa de autoridade e criatividade}

A primeira crítica partiu especialmente das moças: a falta de autoridade e de comando do(a) professor(a). Marcellino (2010) chama a atenção para alguns casos de omissão profissional que são confundidos com liberdade de expressão, no qual o responsável se transforma num "[...] mero espectador, em atitudes que disfarçam um certo comodismo" (p.81). São referidas uma permissividade exacerbada, passividade diante das situações, proximidade extrema com os alunos que se confunde com amizade e comodismo do(a) professor(a). Esses elementos permitem aos rapazes dominar a aula de EF como um todo, em espaço e em conteúdo. Esta falta de domínio de turma pode fazer com que a formação destes alunos fique comprometida, pois eles não têm consciência da importância dos conteúdos e das experiências proporcionadas pela aula de EF. É necessário que o(a) professor(a) haja com mais firmeza e autoridade (não é o mesmo que autoritarismo), mostrando a estes alunos o valor da EF e das suas práticas.

A segunda crítica engloba, mais especificamente, essa monopolização da aula de EF pelos rapazes e pelo futsal. A Política da Igualdade, descrita no inciso II do artigo $3^{\circ}$. das Diretrizes Curriculares Nacionais para o Ensino Médio (BRASIL, 1998) disserta acerca da "[...] igualdade no acesso aos bens sociais e culturais". Segundo a maioria das 
moças e alguns rapazes do estudo, foram poucas as aulas de EF com variação na oferta de atividades e conteúdos.

Sobre a autoridade e domínio de turma do(a) professor(a), os alunos relataram que um(a) ex-professor(a) impôs uma aula de futsal que envolvia a todos e focalizava o aprendizado. Esse exemplo caracteriza o trato educacional do esporte na escola desde uma prática sistematizada e orientada ao desenvolvimento integral dos alunos (SEEMG, 2005). Na visão dos alunos, quando o(a) professor(a) tem interesse e está disposto(a) a ministrar uma boa aula, mesmo com dificuldades, ele(a) consegue. Ademais, os alunos que inicialmente se opunham à proposta foram se adaptando e cessaram de solicitar exclusivamente o futsal na EF.

Outra crítica dos participantes foi a falta de criatividade do(a) professor(a) no trato dos conteúdos da EF. Para os alunos, deve-se variar as atividades nas aulas de EF, pois ela é "sempre igual”. Como dito por E1F: “[...] Coisas diferentes é que interessam”. Deve-se também, segundo os adolescentes, apresentar algo novo e diferente na aula: "Até porque o futebol [futsal] é uma coisa que todos os meninos brincam na rua, queimada todo mundo já brincou na rua, [...] isso é uma coisa que você faz em casa.” $(\mathrm{E} 1 \mathrm{~F})$.

A participação em atividades que envolvessem todos os alunos também foi uma reclamação evidente. $\mathrm{O}$ adolescente tende a se aproximar dos seus pares (BELSKY, 2010); portanto, tem interesse em participar de uma EF envolvente, através da interação com os colegas. Nos Conteúdos Básicos Comuns de Educação Física para o Ensino Médio (SEEMG, 2005) consta que a EF deve possibilitar o desenvolvimento da identidade e a ampliação da capacidade de diálogo e de conhecimento de outrem. Ou seja, a EF é um tempo/espaço propício ao desenvolvimento das relações humanas. A 
este respeito, cabe lembrar que a proximidade e a interação grupal são caras à adolescência (BELSKY, 2010). Em vista disso, a aula de EF pode envolver todos os alunos, com participação simultânea ou sequencial. A experiência profissional prática do primeiro autor deste texto, como professor de EFE e profissional do campo do lazer, aponta que, quando a aula de EF envolve a participação coletiva, o adolescente não se expõe individualmente aos colegas. O momento de aprendizado de algo novo, de exposição do corpo, do risco de participar de atividades que apresentem situações constrangedoras diante de outrem, tudo isso maximiza os mecanismos de público imaginário e fábula pessoal (presentes no egocentrismo adolescente) (BELSKY, 2010).

\section{Sugestões dos adolescentes para uma boa aula de Educação Física}

No GF, além de apontar os pontos negativos da EF na escola, os alunos foram estimulados a pensar e discutir soluções para a melhoria da aula. Isso demonstra que o GF, com todos os seus cuidados e precauções (BARBOUR, 2009), é uma estratégia adequada com adolescentes. Estes, num momento em que se sentem livres para falar e em contato com colegas da sua idade, se sentem à vontade pelo clima de coleguismo que se cria no GF. Acredita-se que, em virtude desses cuidados metodológicos, foi possível detectar, na discussão do GF, cinco aspectos de uma boa aula de EF:

1) Uma boa aula de EF possui professor(a) com “domínio de turma” ou autoridade: Os alunos entenderam que a falta desses aspectos colabora para o(a) professor(a) ceder à pressão dos rapazes e não cobrar a participação das moças. A fórmula parece ser a seguinte: professor não comanda a turma $\rightarrow$ rapazes querem somente o futsal $\rightarrow$ moças não querem participar da aula. $\mathrm{Na}$ visão dos alunos, a EF é um "horário vago com 
professor", durante o qual são realizadas atividades de outras disciplinas, estudo para outros cursos, conversas, fica-se "à toa”, pintam-se as unhas.

2) Uma boa aula de EF recebe mais apoio da escola: Os participantes entendem que a escola não se preocupa com a EF. A quadra de esportes possui um portão trancado com cadeado. Alunos sem professor são colocados neste ambiente para ficarem retidos e, dessa forma, manter a ordem no espaço escolar. Esta estratégia para lidar com a falta de docentes de outras matérias e ocupar os alunos neste tempo é bastante negativa, mas simbólica para ilustrar por que a cidade de Ribeirão das Neves é conhecida como a “cidade-prisão" de Minas Gerais (ANDRADE; MENDONÇA, 2010). Alguns alunos relatam não se importar, mas outros se sentem "presos" na escola. Os adolescentes também referiram a carência de apoio aos materiais didáticos para a EF, como cópias xerográficas, materiais esportivos, bola, rede, etc.

3) Uma boa aula de EF possui mais apoio governamental: Esta crítica é argumentada pelos alunos principalmente quanto ao espaço da EF, já que a escola possui apenas uma quadra. O planejamento e a construção desses espaços parecem não considerar a funcionalidade e espacialidade pertinentes à EFE, não conhecer crianças e adolescentes e nem as necessidades profissionais dos professores de EF. Os alunos sugeriram que fossem disponibilizados materiais adequados para a EF e mais quadras na escola.

4) Uma boa aula de EF desenvolve conteúdos: Na visão dos participantes a EF não transmite conhecimento, não gera questionamentos/debates e não avalia estes aspectos nos alunos. As experiências com trabalhos teóricos não recebem muita atenção por parte 
do(a) professor(a), segundo os adolescentes. Logo, estes não se dedicam efetivamente na realização dos trabalhos, preferindo copiar dos colegas e da Internet: "Eu vou só lá no computador mesmo, copio e colo". Os alunos não veem sentido nesses trabalhos, pois não associam teoria e prática. Um exemplo disso é a fala de um participante: “[...] já pensou se passasse a ser assim, ia ser bem mais interessante, aula prática ser uma aula teórica, entende? Uma em cima da outra, ia ser bem mais divertido e bem mais aproveitado".

5) Uma boa aula de EF tem escola e professor(a) mais motivados: Na percepção dos adolescentes da pesquisa, a instituição escolar não se importa com o desenvolvimento e aprendizagem do aluno, nem com a EF, ainda mais por esta não parecer ser uma disciplina que efetivamente os educa dentro das suas variadas possibilidades de práticas e conteúdos.

\section{A EF como oportunidade de AF na adolescência: Movimento, saúde e beleza}

O próximo ponto a ser discutido acerca do conceito de EF expresso pelos adolescentes diz respeito a associação desta disciplina com a atividade física (AF). Três pontos foram citados pelos adolescentes: a) a EF como forma de AF via movimento; b) a importância da prática de AF para cuidar e manter a saúde; e c) a preocupação estética com a imagem corporal. Os escolares entendem a EF como quebra da rotina da sala de aula: “Ah, não é obrigado a ficar naquela rotina de todo dia ficar sentadinho na sala de aula ouvindo, que fica cansativo", ou "Chega o horário de Educação Física, todo mundo desperta, sabe? Porque você vai fazê o que você quer, entendeu? Cê vai brincar, se distrair sabe? Cê vai se divertir". 
Eles entendem a EF como o momento do despertar na escola associado ao lazer. Nas palavras de um participante, "Educação Física é um lazer dentro de uma escola". Por meio deste entendimento utilitarista do lazer (MARCELLINO, 2010), alguns alunos atribuem a ela o papel de recuperação do ânimo e das energias para as outras aulas: "A gente volta mais animado pra sala, pras outras aulas".

Uma das finalidades da EFE apresentadas pelos Conteúdos Básicos Comuns (SEEMG, 2005) é oportunizar conhecimentos e vivências que objetivem a promoção e a manutenção da saúde e da qualidade de vida. O entendimento de que a EF associa à prática de AF como cuidado à saúde e prevenção de doenças também foi referido pelos adolescentes através de duas formas: a) através do ensino, prática e discussão acerca da AF e dos seus benefícios à saúde como motivador para a prática de exercícios físicos fora do ambiente escolar; e b) como única e exclusiva oportunidade de alguns alunos desfrutarem de AF em suas vidas.

Estudos sobre a EFE mostram que, para muitos alunos, a prática de exercícios se materializa somente no contexto escolar (HARDMAN, 2013). Para ganhos efetivos à saúde via $\mathrm{AF}$, são necessários recursos materiais, humanos, institucionais e conceituais adequados. Nem sempre o que se pratica na aula de EF é suficiente para prevenir, cuidar e manter um bom estado de saúde física. No entanto, a EF, dentro das suas possibilidades teóricas e práticas, pode e deve estimular a AF fora da escola, na busca de um estilo de vida fisicamente ativo.

Sobre a preocupação com o corpo, os adolescentes afirmaram que a prática de AF é uma forma de alcançar boa aparência física e de sentir-se bem com ela, por exemplo, mediante exercícios em academia de ginástica/musculação. A este respeito, cabe considerar que na adolescência o corpo passa por mudanças significativas. Somado 
a isso, há, com o egocentrismo adolescente, os processos de fábula pessoal e de público imaginário (BELSKY, 2010), responsáveis por realçar as preocupações sobre o que os outros podem estar pensando sobre ele. Outro ponto é a identificação e aproximação com colegas a partir de uma ideia de imagem corporal ideal e socialmente aceita (o belo, o forte, o bem cuidado); para o adolescente, ser aceito no grupo de pares é quase uma meta diária (BELSKY, 2010).

Requixa (1980) aponta que há uma tendência para a diminuição da prática de AF após o ensino fundamental. Portanto, a AF deve ser valorizada e incentivada na adolescência. Ademais, Alves et al. (2005) e Azevedo et al. (2007) mostram que adultos que praticam atividades físicas regularmente já possuíam este hábito na adolescência, ou seja, mantiveram-no. É possível que a EFE influencie a continuidade da AF na vida adulta.

\section{Como o adolescente conecta lazer e EF}

A análise das entrevistas individuais para a questão "Em sua opinião, existe alguma relação entre Lazer e EF?" gerou seis categorias. Fazer o que gosta (4 rapazes e 3 moças) abrangeu também os conteúdos prazer, gostar, felicidade, alegria e faz bem. Diversão envolveu 2 rapazes e 5 moças, e Esportes/jogos (3 rapazes e 4 moças) incluiu esporte, jogos, jogar bola e queimada. As demais categorias foram distração/relaxamento/tranquilidade, exercício/movimento, e outras respostas.

No GF, a relação lazer-EF foi agrupada nos seguintes temas: a) exercitar com amigos/alguém; b) distração e bem-estar via esporte; c) EF lembra esportes, prática que facilita interação com outrem; d) momento de alívio, bem-estar fora do tédio da rotina escolar/sala de aula; e) o lazer pode movimentar a aula de EF e promover interação; f) 
momento que desliga/distrai do cotidiano. Os alunos participantes do GF argumentaram que a EF se transforma em lazer quando é organizada e capaz de incluir todos os alunos, com incentivo do professor, proporcionando prazer. Além disso, apontaram que a EF já seria um lazer se fosse mais dedicada às práticas da $\mathrm{EF}$, no lugar de outras atividades.

Para os sujeitos desta pesquisa que perceberam uma aproximação entre EFE e lazer, ela ocorre por três motivos: a) pela possibilidade de se fazer o que o gosta; b) pela diversão vivenciada nestes momentos; e c) pela vivência de esportes/jogos. E para que a aula de EF se transforme em momento de lazer na escola, a EF deve: a) promover o coleguismo nos alunos; b) proporcionar prazer; c) ser diversificada; d) romper a rotina de sala de aula; e e) não separar rapazes e moças nas atividades.

Como ressaltado por Gomes e Elizalde (2012, p.84), o lazer se constitui na relação de três dimensões: a ludicidade, as manifestações culturais e o tempo/espaço social. Para os adolescentes a EF é lazer porque envolve conteúdos lúdicos, prazerosos. A necessidade de espaço adequado para a EF rompe com o uso cotidiano do espaço escolar via sala de aula. $\mathrm{O}$ fato de alterar o ambiente, da sala de aula para a quadra, e a possibilidade de ensino-aprendizagem sem materiais didáticos convencionais, colabora para a compreensão da aproximação lazer e EF. Representa, assim, uma oportunidade de ensino prazeroso e divertido. Há, também, a aproximação do tempo da EF como tempo de lazer: mesmo como um tempo cronometrado e medido, este intervalo permite o afastamento do contexto escolar mais tradicional - a sala de aula.

Nesse sentido, destaca-se o conceito de semilazer de Dumazedier (2008), enquanto atividade parte mandatória e parte desinteressada, uma atividade mista em que o lazer se confunde com uma obrigação institucional. Assim, para os adolescentes 
participantes deste estudo, a EF é um semilazer, posto que obrigatória e prazerosa para a maioria dos alunos.

Considerado um fenômeno tipicamente moderno, o lazer pode atender as necessidades e demandas do ambiente escolar, devido à sua possibilidade de servir para alívio das tensões de sala de aula e reposição de energias. De fato, alguns participantes da pesquisa visualizam a EF como tempo para reposição de energias. Essa associação remete ao que Marcellino (2010) discute nas abordagens funcionalistas de tipo compensatória e utilitarista, condizentes ao entendimento comum de que as aulas de EF são momentos de lazer na escola, pois as compreendem como quebra da rotina e recuperação de forças.

Com relação aos conteúdos da EF com possibilidades de abordar o lazer, destacam-se as atividades físico-esportivas, citadas pelos adolescentes desta pesquisa. São atribuídas àqueles que as praticam com uma atitude de "livre adesão", e em espaço/tempo disponíveis da esfera das obrigações. Por isso há sua aproximação a uma manifestação de lazer (MARCELLINO, 2006). No entanto, a "escola não é tempo nem ‘equipamento’ de lazer” (VAGO, 2009, p.26).

A EF pode, na verdade, ser contexto de orientação, entendimento e discussão acerca do tema lazer, com atividades que possam facilitar a compreensão e a vivência do lazer para além dos muros da instituição escolar. Isso não significa afirmar que os estudantes estão errados em sua percepção, mas sim significa levar em consideração que o entendimento de lazer proposto na literatura científica como tempo/espaço sem obrigações (GOMES; ELIZALDE, 2012) ou como tempo livre (MARCELLINO, 2010) não inclui o tempo-espaço da aula de EF. 
Uma das finalidades da EF no ensino médio é educar para o lazer, conforme os Conteúdos Básicos Comuns da EF (SEEMG, 2005, p. 17). O valor dado ao lazer por este documento é evidente. Assim, e ensino médio passou a contemplar o tempo de nãotrabalho, de não-estudo. O presente trabalho considera que o lazer deve ser tratado pela EFE não somente como fim, mas também como instrumento reflexivo de educação.

\section{Considerações Finais}

O objetivo da presente pesquisa foi alcançado, pois foram identificadas e analisadas as percepções dos adolescentes acerca da EF escolar, do lazer e da associação entre elas. Os alunos adolescentes entendem o lazer como o momento de fazer o que gostam, de serem livres e de usufruírem de práticas divertidas. Ficou evidente, também, a necessidade da vivência em grupo. Ademais, foi demonstrado, metodologicamente, que o GF proporciona a identificação de experiências compartilhadas, o debate sobre as mesmas e a possibilidade de criar soluções e alternativas aos problemas vivenciados quanto ao lazer e à EFE.

A principal crítica dos participantes à aula de EF foi a ausência de autoridade do(a) professor(a) na forma de falta de "domínio de turma". Ainda foram relatados a falta de atenção a esta disciplina por parte da escola e do poder público. Portanto, os alunos percebem que a EF está sem o suporte necessário no ambiente escolar. Os participantes relataram também que a EF é principalmente uma disciplina relacionada à prática de AF como promoção e manutenção da saúde.

Sobre a relação lazer-EF, os adolescentes mencionaram que a aula de EF é o momento de lazer mediante quebra da rotina, pois usa materiais e espaços diferenciados nesta disciplina, na comparação com as demais. No entanto, a EF, para além de 
momentos de diversão e relaxamento, deve ser vista também como um contexto de desenvolvimento e aprendizagem, com conteúdos próprios, e que podem ser conectados ao contexto social destes adolescentes. O fato desta disciplina fazer parte de um momento de compromisso do adolescente também é relevante e, nessa perspectiva, a EF pode ser considerada como semilazer, pois é uma obrigação da qual os alunos gostam.

Quanto às limitações desta pesquisa, pode-se destacar a realização de um único GF. Outros grupos focais, com alunos do primeiro e do terceiro ano, teriam dado uma visão mais completa das percepções e experiências de lazer e de EF no ensino médio da escola envolvida. Outra limitação é o envolvimento de uma única escola, e outras realidades escolares da mesma cidade poderiam apresentar vivências distintas. Por fim, outra limitação foi a ausência de entrevista com o(a) professor(a) de EF da escola, que não pôde comentar a visão dos adolescentes acerca da sua prática profissional. Esta comparação pode ser bastante rica para futuros estudos, visto que o presente trabalho foi concebido com o interesse de investigar o aluno de EF e sua percepção sobre o lazer e a EF.

Espera-se que esta pesquisa possa contribuir para a realização de futuros estudos científicos. Sugere-se uma discussão entre o lazer e a adolescência a partir de outros contextos, tais como os que possam envolver trabalhos e/ou cursos de formação, a fim de se entender como se inicia o processo de materialização do lazer num momento no qual as obrigações escolares e profissionais se apresentam mais evidentes. Sobre o lazer e EF, sugere-se um trabalho que tenha como objetivo a visão do professor de EF sobre o lazer, pois se acredita que sua compreensão profissional acerca do lazer possa influenciar no desenvolvimento deste tema nas suas aulas. 
Sobre a EF e adolescência, sugere-se um estudo que aborde como os conteúdos da $\mathrm{EF}$ podem influenciar nas práticas e vivências, em termos de AF, fora do ambiente escolar. Tal compreensão pode orientar na prática profissional da elaboração de uma organização curricular da EF orientada para a criação, prática e manutenção de hábitos saudáveis de vida. E envolvendo a relação central deste estudo, abordando os três temas supracitados, sugere-se um trabalho que seja capaz de abordar a fase inicial da adolescência (isto é, a puberdade). Acredita-se que esse momento de turbulência, em especial das transformações físicas, pode evidenciar novos dados da relação EF e lazer e ajudar a profissionais de ambas as áreas a pensar, refletir e desenvolver suas práticas com estes sujeitos.

E ainda, a partir das informações levantadas por este estudo, tem-se a intenção de trazer à tona a possibilidade de ferramentas e meios para desenvolver nestes adolescentes o pensamento crítico no entendimento do lazer como um direito social. Acima de tudo, que estes futuros adultos busquem o lazer para suas vidas a partir das práticas oferecidas e vivenciadas dentro e fora da escola.

Enfim, cabe a todos aqueles envolvidos na interface lazer, EF e adolescência, seja na teoria e/ou na prática, recordar que o adolescente é um ser humano como outro qualquer, com seus anseios, desejos, vontades de experimentar novas possibilidades e, principalmente, de participar ativamente do contexto no qual se insere. Dessa forma, é um sujeito a quem devemos dar o direito de se expressar, se envolver em desafios, e ainda, pelos diversos profissionais que possam ter como foco os sujeitos nesta fase da vida, criar condições que ampliem o significado e a reflexão acerca de uma cidadania ativa, em especial voltada aos direitos sociais, com foco no direito ao lazer. 


\section{REFERÊNCIAS}

ALVES, J.G.B. et al. Prática de esportes durante a adolescência e atividade física de lazer na vida adulta. Rev. Bras. Méd. Esporte, v. 11, n. 5, p. 291-294, set/out, 2005.

ANDRADE, L.T.; MENDONÇA, J.G. Explorando as consequências da segregação metropolitana em dois contextos socioespaciais. Caderno Metrópole, São Paulo, v. 12, n. 23, p. 169-188, jan/jun 2010.

ASPESI, C.C. et al. A ciência do desenvolvimento humano: uma perspectiva interdisciplinar. In: DESSEN, M.A; COSTA JR, A.L. A ciência do desenvolvimento humano: tendências atuais e perspectivas futuras. Porto Alegre: Artmed, 2005. 278p.

AZEVEDO, M.R et al. Tracking of physical activity from adolescence to adulthood: a population based study. Revista Saúde Pública, v.41, n. 1, p. 69-75, 2007.

BARDIN, L. Análise de conteúdo. São Paulo: Edições 70, 2011. 279p.

BARBOUR, R. Grupos focais. Porto Alegre: Artmed, 2009. 216 p.

BELSKY, J. Desenvolvimento Humano: Experienciando os ciclos da vida. Artmed, 2010.608p.

BONATO, T.N.; SARRIERA, J.C.; WAGNER, A. O lazer na adolescência. In: SARRIERA, J.C., PARADISO, A.C. Tempo livre e lazer na adolescência: promoção de saúde, intervenção e pesquisa. Porto Alegre: Sulina, 2012. 207p.

BRASIL. Resolução CEB n. 3, de 26 de junho de 1998. Diretrizes Curriculares Nacionais para o Ensino Médio (1998). Disponível em:

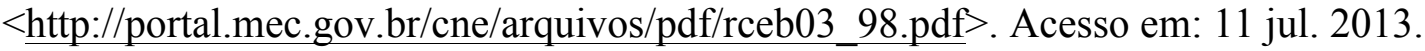

DUMAZEDIER, J. Lazer e cultura popular. São Paulo: Perspectiva, 1976.

. Sociologia empírica do lazer. 3. ed. São Paulo: Perspectiva: SESC, 2008.

Valores e conteúdos culturais do lazer. São Paulo: SESC, 1980.

FORMIGA, N.S.; AYROZA, I.; DIAS, L. Escala das atividades de hábitos de lazer: construção e validação em jovens. PSIC - Revista de Psicologia da Vetor Editora, v.6, n. 2, p. 71-79, Jul./Dez. 2005.

FREITAS, M. V. de. Juventude e Adolescência no Brasil: referências conceituais. São Paulo: Ação Educativa, 2005.

GOMES, C.L. Lazer e formação profissional: saberes necessários para qualificar o processo formativo In: FORTINI, J.L.M., GOMES, C.L., ELIZALDE, R. Desafios e perspectivas da educação para o lazer. Belo Horizonte: Editorial SESC/OTIUM, 2011. 440p. 
GOMES, C.L.; ELIZALDE, R. Análise teórico-conceitual da recreação e do lazer na América Latina. In: Horizontes latino-americanos do lazer / Horizontes latinoamericanos del ócio. GOMES, C.L.; ELIZALDE, R. (Org.). Belo Horizonte: Editora UFMG, 2012. 343p.

HARDMAN. C.M. et al. Participação nas aulas de educação física e indicadores de atitudes relacionadas à atividade física em adolescentes. Rev Bras Educ Fís Esporte, v. 27, n. 4, p. 623-31, 2013.

MARCELLINO, N.C. Lazer e educação. 16. ed. Campinas: Papirus, 2010. 136p.

. et al. $\mathrm{O}$ conceito de lazer nas concepções da educação física escolar: o dito e o não dito. In: CONGRESSO BRASILEIRO DE CIÊNCIAS DO ESPORTE - CBCE, 12. Anais... Caxambu: CBCE, 2001, p. 1-9.

Lazer e educação física. In: DE MARCO, A. (Org.), Educação Física: cultura e sociedade. Campinas: Papirus, 2006, p. 47 - 69.

MUNNÉ, F.; CODINA, N. Ocio y tiempo libre: consideraciones desde uma perspectiva psicosocial. Revista Licere, v. 5, n. 1, p 59-72, 2002.

OZELLA, S. Adolescência: uma perspectiva crítica. In: CONTINI, M.L.J.; KOLLER, S.H.; BARROS, M.N.S. Adolescência e Psicologia: concepções, práticas e reflexões críticas. Rio de janeiro: Conselho Federal de Psicologia, 2002. 144p.

PARADISO, A.C. et al. Tempo livre e projeto de vida: uma proposta orientada aos adolescentes. In: SARRIERA, J.C., PARADISO, A.C. Tempo livre e lazer na adolescência: promoção de saúde, intervenção e pesquisa. Porto Alegre: Sulina, 2012. 207 p.

PRATA, E.; SANTOS M. Lazer e Uso de Substâncias Psicoativas na Adolescência: Possíveis Relações. Psicologia: Teoria e Pesquisa. v. 23 n.1, p. 043-052, 2007.

REQUIXA, R. Juventude e tempo livre em países em desenvolvimento. Boletim de intercâmbio, Rio de Janeiro, v.1, n. 1, p. 7-22, jan-mar., 1980.

ROJEK, C. 2011. O lado obscuro do lazer: formas anormais. In: FORTINI, J.L.M., GOMES, C.L., ELIZALDE, R. Desafios e perspectivas da educação para o lazer. Belo Horizonte: Editorial SESC/OTIUM, 2011. 440p.

SARRIERA, J.C. et al. Significado do tempo livre para adolescentes de classe popular. Psicologia, ciência e profissão, v.27, n. 4, p. 718-729, 2007.

SEEMG. SECRETARIA DO ESTADO DE EDUCAÇÃO DE MINAS GERAIS. Conteúdos Básicos Comuns - Educação Física: Ensinos Fundamental e Médio (2005). Acesso em: 13/03/2012. Disponível em: $<$ http://crv.educacao.mg.gov.br/sistema_crv/minicursos/ed_fisica_em/capa_introducao. htm>. 
SHAFFER, D.R.; KIPP, K. Psicologia do Desenvolvimento: Infância e Adolescência. São Paulo: Cengage Learning, 2012. 920p.

SILVA, K.; XAVIER, D. As representações sociais do lazer por estudantes do ensino médio: contribuições para a construção de novas práticas em educação física escolar. In: ENCONTRO FLUMINENSE DE EDUCAÇÃO FÍSICA ESCOLAR: Lazer e Educação Física Escolar.10. Anais...Niteroí: UFF/Departamento de Educação Física e Desportos, 2006. p. 90-97.

SOARES, C.L. et al. Metodologia do ensino da Educação Física. São Paulo: Cortez, 1992.

VAGO, T.M. Pensar a educação física na escola: para uma formação cultural da infância e da juventude. Cadernos de Formação RBCE, v.1, n.1, p. 25-42, set. 2009.

\section{Endereço dos Autores:}

Vagner Miranda da Conceição

Universidade Federal de Minas Gerais

Escola de Educação Física, Fisioterapia e Terapia Ocupacional

Programa de Pós-Graduação Interdisciplinar em Estudos do Lazer

Av. Antonio Carlos 6627 - Campus UFMG - Pampulha.

Belo Horizonte, Minas Gerais. CEP. 31.270-901

Endereço eletrônico: eefvagner@hotmail.com

Luciana Karine de Souza

Universidade Federal de Minas Gerais

Escola de Educação Física, Fisioterapia e Terapia Ocupacional

Programa de Pós-Graduação Interdisciplinar em Estudos do Lazer

Av. Antonio Carlos 6627 - Campus UFMG - Pampulha.

Belo Horizonte, Minas Gerais. CEP. 31.270-901

Endereço eletrônico: lukarides@gmail.com 